\title{
AFETIVIDADE E COGNIÇÃO E O DESENVOLVIMENTO DA RESILIÊNCIA EMPREENDEDORA DO MÉDICO
}

Ana Luisa Dal Belo Carneiro Leão ${ }^{1}$

Vânia Maria Jorge Nassif ${ }^{2}$

\footnotetext{
${ }^{1}$ Universidade Federal de Sergipe/ Departamento de Administração

${ }^{2}$ Mestrado e Doutorado / Programa de Pós-Graduação em Administração / Universidade Nove de Julho
} 


\section{AFETIVIDADE E COGNIÇÃO E O DESENVOLVIMENTO DA RESILIÊNCIA EMPREENDEDORA DO MÉDICO}

Resumo: O estudo objetiva analisar as estratégias de enfrentamento influenciadas pela afetividade e cognição para explicar o desenvolvimento da resiliência empreendedora na trajetória da carreira dos médicos. Parte do pressuposto de que o bem-estar dos médicos e a sobrevivência dos seus empreendimentos estejam relacionados à sua capacidade de persistir às adversidades. Trata-se de uma pesquisa qualitativa de caráter exploratório e descritivo, utilizando-se de entrevistas individuais com 32 médicos das áreas pública e privada e oito alunos de um curso de medicina de São Paulo. As principais adversidades identificadas estão relacionadas às condições de trabalho, às dificuldades inerentes à profisssão e à gestão de negócios. As estratégias de enfrentamento estão pautadas nas capacidades cognitivas. Os resultados evidenciaram a indissociabilidade da afetividade e capacidades cognitivas. Também preenche aos ensejos pontuados na literatura que sinalizam a necessidade da realização de pesquisas em contextos específicos, para explicar o desenvolvimento da capacidade de resiliência.

Palavras-chave: Estratégias de Enfrentamento. Resiliência. Afetividade. Capacidades Cognitivas.

\section{$1 \quad$ Introdução}

Os estudos sobre a resiliência empreendedora têm se tornado uma área emergente e interessante aos formuladores de políticas, desenvolvimento de organizações, profissionais e acadêmicos (McNaughton \& Gray, 2017). Essa temática apresenta uma estreita relação com as adversidades (Herbane, 2015), que podem decorrer das barreiras aos negócios (Halkos et al., 2018), estilos de liderança (Sommer, Howell \& Hadley, 2016; Arnold \& Hobson, 2018), julgamentos e heurísticas (Osiyevskyy \& Dewald, 2015).

O encaminhamento desta pesquisa dirige-se para profissionais médicos, campo de grande relevância e a ser investigado dada natureza do contexto e a pluralidade do seu papel, caracterizado pelos cuidados aos pacientes e ações empreendedoras. Azzam (2018) sugere que o médico se comporta de modo diferente ao utilizar elementos de constructos teóricos para o seu desenvolvimento; e ao buscar desafios decorrentes de oportunidades inesperadas, assume o papel empreendedor.

Embora se conceba a existência de uma possível diferença entre o médico (profissional liberal) e o médico empreendedor (Azzam, 2018), neste estudo busca-se analisar os antecedentes e consequentes das adversidades que emergem na sua trajetória da carreira, bem como as EE adotadas por esses profissionais vislumbrando a superação das mesmas.

Barrett (2006) sugere que para identificar os aspectos afetivos é necessário compreender a experienciação do afeto diante de uma situação ou contexto específicos; e que a história de vida do indivíduo, sua educação, sua relação com a família e com a comunidade vão se desenvolvendo com o passar dos anos. Igualmente importante é a reflexão sobre a concepção de que "o empreendedorismo é uma experiência altamente pessoal que pode ser definida em termos de fluxo temporal de eventos únicos e novos que são ricos em afeto" (Morris et al., 2006, p. 15). A Teoria dos Eventos Afetivos de Weiss e Beal (2005), por exemplo, permite argumentar que os empreendedores chegam à experiência de criação de empreendimentos com um estoque de experiências de vida que vão se avolumando na medida em que vivenciam as experiências empreendedoras. Esse desenvolvimento pode contribuir positivamente, tanto na regulação emocional quanto na formulação de estratégia de enfrentamento.

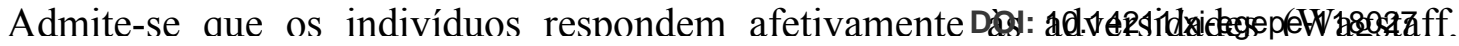


paixăo, humor e temperamento) seja fundamental para que se compreenda o papel da capacidade cognitiva (por exemplo, percepção, a inteligência, o aprendizado, a criatividade, o raciocínio e a capacidade de resolver problemas) no enfrentamento das adversidades (Williams \& Vorley, 2014; Dahles \& Susilowati, 2015; Adomdza e Dedeke (2017)). Apesar disso, não foram identificados estudos focados na afetividade e cognição como influenciadores das estratégias de enfrentamento - EE nos contextos médicos. Também não foi identificado, até o momento, em que fase da trajetória da carreira médica esse profissional passa a se dedicar ao papel de empreendedor, seus desafios e adversidades.

Dessa forma, o presente estudo tem por objetivo analisar as EE influenciadas pela afetividade e cognição para explicar o desenvolvimento da resiliência empreendedora na trajetória da carreira dos médicos. Parte dos seguintes pressupostos: (1) o bem-estar dos médicos e a sobrevivência dos seus empreendimentos estão relacionados à sua capacidade de persistir às adversidades; (2) as capacidades afetiva e cognitiva desempenham um papel central nas escolhas das EE; (3) a área da saúde é considerada um dos contextos mais complexos e adversos e as forças da adversidade são tão persistentes e dinâmicas (Garbuio, \& Wilden, 2018) que nem sempre há soluções imediatas para o problema à vista.

Para atender ao objetivo proposto, foram entrevistados 32 médicos e oito alunos de uma escola privada de Medicina da cidade de São Paulo. Do ponto de vista da prática, buscase compreender as diferentes percepções nas três fases da trajetória da carreira médica para explicar como esses profissionais desenvolvem a capacidade de resiliência. Esse entendimento perpassa pela identificação dos afetos e das capacidades cognitivas manifestadas frente às adversidades. Os resultados desse estudo também contribuem para identificar as diferentes estratégias adotadas pelos médicos no enfrentamento das adversidades no trabalho e nos seus empreendimentos.

\section{Fundamentação Teórica}

2.1 Resiliência Empreendedora, Estratégias de Enfrentamento (EE) e a Adversidade

A literatura traz evidências de que os primeiros estudos envolvendo a temática resiliência decorrem da engenharia, física e ecologia, seguido pela psicologia social e do desenvolvimento, geografia social e econômica, economia ambiental e, por último, management (McNaughton \& Gray, 2017). Na área de negócios os estudos sobre resiliência vêm sendo norteados pela perspectiva de compreender a capacidade de recuperação das organizações e dos indivíduos frente as adversidades (Van Der Vegt, Essens, Wahlström, \& George, 2015).

A resiliência empreendedora relaciona-se às forças individuais dos empreendedores Duchek (2018). Ela pode ser definida como a capacidade dos indivíduos de suportar o estresse e lidar com a pressão. Essa pressão é oriunda de diversos contextos (por exemplo, mercado, localidade, ambiente, cultura, sucesso ou fracasso, gênero), fatores ambientais (por exemplo, terremotos e inundações) ou de choques exógenos, como as crises financeiras e recessões (Bakas, 2017; Menéndez-Blanco \& Montes-Botella, 2017; Duchek, 2018). Também é concebida como a capacidade dos empreendedores de mitigar os riscos de turbulência e reorganizar um modelo de negócio enquanto sofre mudanças (Micu et al., 2018).

A capacidade de recuperação é considerada uma característica desejável a todos envolvidos no enfrentamento das adversidades (Luthans, Avey, Avolio, \& Peterson, 2010; Linnenluecke, 2015) e necessária para a sua adaptação em ambientes caracterizados pela instabilidade e incerteza (Limnios, Mazzarol, Ghadouani, \& Schilizzi, 2014). Na perspectiva de Bernard e Barbosa (2016) a resiliência contempla os conceitos de locus de controle, necessidade de realização, enfrentamento, resistência, talento cognitivo, habilidades inovadoras, confiança e inteligência emocional do empreendedor. Estas diferentes facetas

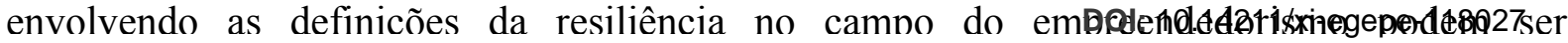


liberais. Trata-se de uma capacidade positiva que o individuo tem ao adotar novas rotınas quando confrontado por ameaças e oportunidades (Dewald \& Bowen, 2010).

Embora haja a impressão de que as pessoas vivenciam as adversidades da mesma forma, com afetos negativos, há evidência de que os enfrentamentos podem aliviar o estresse e promover resultados psicológicos positivos (Shepherd, Saad, \& Wincent, 2019). As EE são as respostas frente a uma situação adversa (Uy, Foo \& Song, 2013). Elas decorrem da interação entre o indivíduo e o ambiente e apresentam uma estreita relação com a personalidade e com as experiências de vida de cada um (Morero, Bragagnollo \& Santos, 2018).

Importante compreender que a eficácia das EE depende das características individuais, contexto investigado e das experiências de vida. Não é de se surpreender que os estudiosos tenham voltado sua atenção para demonstrar a importância de investigar a capacidade de resiliência em contextos específicos, a partir das EE (Shepherd, Saad, \& Wincent, 2019), como é o caso dos ambientes hospitalares. Por adversidade entende-se situações que podem impactar negativamente no desenvolvimento de uma tarefa, da empresa e da comunidade (Osiyevskyy \& Dewald, 2015; Andrews, 2017).

Para encontrar forças frente às adversidades, os indivíduos recorrem às capacidades e recursos disponíveis, incluindo as afetivas, cognitivas, sociais e estruturais (Sommer, Howell \& Hadley, 2016). Os afetos são fundamentais no desenvolvimento da capacidade de resiliência (Kaplan, Laport, \& Waller, 2013), na escolha das EE e no processo de adaptação do indivíduo. A reavaliação positiva (Gross \& John, 2003), por exemplo, é uma capacidade individual que proporciona consequências adaptativas para o afeto, relações e o bem-estar individual. Elas podem significar mais do que os eventos adversos por contribuírem para o enfrentamento e para a superação das adversidades (Masten, 2001).

Lazarus e Folkaman (1984) sugeriram que a cognição é uma pré-condição para a experienciação da emoção. Para eles, ao analisar a capacidade cognitiva do indivíduo é possível interpretar as suas experiências subjetivas e EE. Smedley (2018) sugere ser importante usar os sentidos para obtenção do engajamento e do compartilhamento de informações como as EE. Ele argumenta que o aprendizado pode ajudar no desenvolvimento das competências empreendedoras, incluindo as associadas à resiliência (Michelmore \& Rowley, 2010); e a perseverança pode contribuir para reavaliar como a adversidade vem sendo percebida pelos indivíduos (Van Gelderen, 2012).

Smith e Hollinger-Smith (2015) examinaram o efeito moderador da resiliência pessoal nas EE orientadas para as tarefas, evitação e emoção, sobre as medidas de depressão, ansiedade, estresse, afeto positivo, afeto negativo e satisfação com a vida. Para eles, a eficácia de qualquer EE depende da resiliência pessoal.

No contexto médico, a resiliência empreendedora ultrapassa os limites das dificuldades enfrentadas pelos médicos ao abrirem suas empresas, clínicas ou hospitais. Ela contempla a necessidade constante de gerar novas ideias, inovar, superar os obstáculos relativos à gestão do negócio e os desafios de conciliar as atividades relacionadas aos cuidados com a saúde do paciente, com as atividades empreendedoras e vida pessoal. Para conciliar essa demanda é preciso ter resiliência na execução do seu trabalho.

A estreita relação entre o desenvolvimento da capacidade de resiliência empreendedora e a persistência individual foi mencionada por Cardon, Wincent, Singh, \& Drnovsek (2005). De fato, os eventos adversos contribuem para explicar a dinâmica da capacidade de resiliência dos indivíduos (Bernard \& Barbosa, 2016). Patzelt \& Shepherd (2011) sugeriram que os trabalhadores por conta própria, neste caso os médicos, aceitam mais facilmente as consequências emocionais negativas decorrentes da sua escolha de carreira e por isso lidam positivamente com as suas consequências. A dinamicidade das EE e da

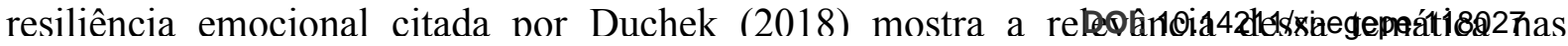




\subsection{O Contexto Médico}

A escolha do setor médico para a realização da pesquisa deve-se ao seu contexto singular e diversificado, cuja representatividade no Produto Interno do País - PIB (9\%), vem crescendo nos últimos dez anos (Carvalho, 2017) e o crescimento dos novos modelos de negócios no setor médico exige a adaptação e enfrentamento destes profissionais. As implicações das capacidades afetivas nas EE (Patzelt \& Shepherd, 2011) e no desenvolvimento da capacidade de resiliência ganham relevância no contexto médico e o estudo de Zonta, Robles e Grosseman (2006), realizado com os estudantes de Medicina da UFSC evidencia a necessidade de melhoriada qualidade de vida destes estudantes. Kanno, Bellodi e Tess (2012) investigaram as dificuldades e as EE dos profissionais da Estratégia da Saúde da Família (ESF) frente às demandas médico-sociais apresentadas pelos usuários em seu cotidiano de trabalho. Ambos os estudos focaram nas EE para minimização dos agentes estressores. Cano (2008) em uma investigação sobre as vivências, concepções e as EE psicológica dos médicos, identificou que estes profissionais focam na emoção e na espiritualidade como meios de reduzir os agentes estressores.

$\mathrm{O}$ que se percebe, ao analisar estes artigos, é que a maioria deles não foca as EE influenciadas pelas capacidades afetiva e cognitiva. Tão pouco as experiências de vida dos indivíduos e as implicações na percepção das adversidades. Os estudos também não evidenciam os comportamentos de adaptação e superação dos médicos frente às adversidades relacionadas ao seu papel enquanto empreendedor. Dessa forma, essa pesquisa busca preencher as lacunas ora identificadas, investigando as capacidades afetivas e cognitivas no contexto médico. Assim, faz parte deste estudo, analisar as implicações da trajetória de carreira dos médicos, as influências por eles recebidas e o quanto elas contribuem no enfrentamento das adversidades e, consequentemente, no desenvolvimento da capacidade de resiliência empreendedora desses profissionais.

\section{Metodologia}

Em função do objetivo proposto e do pouco conhecimento sobre as EE influenciadas pelas capacidades afetivas e cognitivas para explicar o desenvolvimento da resiliência empreendedora do médico, uma pesquisa com propósitos exploratórios e descritivos foi desenvolvida. A pesquisa se caracteriza como qualitativa básica (Merriam,2009). Três fases distintas da carreira médica foram analisadas, atendendo aos pressupostos de Creswell (2014) sobre a amostragem intencional. A fase 1 é caracterizada pelo período de formação e desenvolvimento da carreira. Nessa fase a coleta de dados foi feita por intermédio de um grupo focal (GF) realizado com oito alunos do último ano da escola de Medicina de uma instituição privada de São Paulo. A fase 2 representa o período de reconhecimento e busca por estabilidade na carreira. Nessa etapa buscou-se entrevistar 12 médicos com até dez anos de formados. A fase 3 da carreira representa o período de senioridade da profissão e foram entrevistados 20 médicos com mais de 10 anos de formados. As três fases da carreira foram trianguladas. Por meio de uma rede de networking da categoria, foi possível estabelecer contato com os participantes da pesquisa.

Para a realização do GF valeu-se dos pressupostos de Barbour (2009) que considera que os participantes conversem entre si, de forma interativa e focada no tema específico.

Um Termo de Consentimento foi assinado por cada médico e foram prestadas as informações sobre os objetivos da pesquisa, voluntariedade na participação, forma de utilização dos dados, garantia de sigilo e segurança das informações, além de ter sido solicitada a permissão para a gravação em áudio. A entrevista semiestruturada seguiu, ainda, um modelo proposto por Deliens et al. (2015), contendo uma pergunta introdutória; questões que retratassem uma transição para o objetivo principal, questões-chave e a finalização.

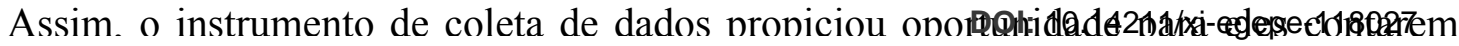


dificuldades entrentadas no exercício da protissão. Nas questōes-chave buscou-se o aprofundamento com perguntas relacionadas aos afetos experienciados frente as dificuldades, formação médica e comportamento resiliente empreendedor.

Os áudios das entrevistas foram transcritos, gerando 416 páginas. Nesse momento, cada um dos entrevistados recebeu uma denominação, passando a serem identificados por E1, E2, E3 [...], até E32. Os alunos participantes do GF foram identificados por P1a, P2a, P3a [...], até P8a. Para a análise de dados, foi usada a análise de conteúdo proposta por Bardin (2011), com o apoio do software Atlas Ti para a busca, organização e categorização das interpretações.

Os dados foram examinados para instâncias recorrentes e um agrupamento feito, por meio de um sistema de codificação aberto, com 362 trechos selecionados e 145 códigos diferentes. Na sequencia, os temas foram agrupados em conceitos e organizados em categorias principais. Houve o agrupamento em 15 códigos de primeira ordem: contexto institucional, aspectos educacionais, socioeconômico e cultural, dificuldades inerentes à profissão, condições de trabalho, gestão de negócios, impacto na vida pessoal, aspectos circunstanciais, foco nos aspectos afetivos e cognitivos, apoio social, capacidades e atributos individuais.

Uma análise sistemática de segunda ordem foi realizada para visualizar os dados em um nível superior de abstração teórica (Gioia, Corley \& Hamilton, 2013), comparando os conceitos de primeira ordem em categorias que representassem os conceitos teóricos emergentes. Foram criados quatro códigos de segunda ordem: antecedentes, tipos e consequentes da adversidade, tipos de EE. Depois de examinar novamente as categorias, os alinhamentos e sobreposições e as relações entre os conceitos de primeira e de segunda ordem que poderiam ser agrupados em categorias complementares, emergiram 2 dimensões: adversidades e estratégias de enfrentamento, totalizando seis códigos para serem analisados.

\section{Resultados}

\subsection{Adversidades}

As adversidades, nesse estudo, relacionam-se às situações que podem impactar negativamente no desenvolvimento da profissão médica e três categorias foram analisadas: antecedentes, tipologia e consequentes das adversidades. Os antecedentes das adversidades, focaram os aspectos institucionais, se hospital público ou privado; os aspectos educacionais, envolvendo a formação e a educação empreendedora; e aspectos socioeconômico e cultural.

Sobre os aspectos institucionais, foi possível identificar que os hospitais públicos foram os mais citados no quesito das condições geradoras de estresse. Nesses hospitais os médicos precisam estar em constante estado de alerta, além de serem criativos quanto ao uso de mecanismos de enfrentamento da crise. São ambientes singulares, com problemas relacionados à organização, gestão e ao acesso aos recursos básicos necessários para o cuidado com os pacientes. O que mais incomoda os médicos é a dificuldade de chegarem a um diagnóstico e tratamento adequado aos pacientes. Além disso, o fluxo de pacientes é incompatível com a oferta de recursos humanos. As falas de E4 e E24 ilustram essa situação: "na área pública, o risco é de não poder absorver o paciente para o sistema [...] o sistema pode estar sobrecarregado [...] é muito volume, às vezes não tem nem tempo de ficar procurando mais, investigando o paciente, tem que pular para o próximo" (E4); "na rede pública, a maior dificuldade é do ponto de vista estrutural, você tem que resolver os problemas dos doentes com pouco recurso e muitas vezes com ausência deles" (E2). Nos hospitais privados os sentimentos dos médicos parecem ser mais positivos. As possibilidades de cuidados oferecidos aos pacientes minimizam as condições geradoras de estresse que, na maioria das vezes, são inerentes à profissão. O trabalho nestes hospitais parece fluir, porém, o maior

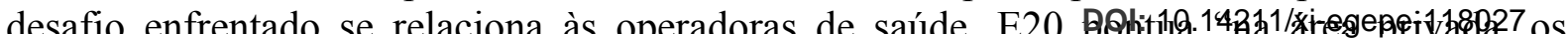


grande desatio é lidar com que os convênios - eles são os ditadores das regras do exercício da profissão, tem que agir de acordo com as políticas deles".

Os aspectos educacionais mostraram-se importantes na percepção dos médicos. A formação universitária foi mencionada pelos médicos pertencentes às fases 2 e 3 da carreira, como geradora de tensão, insegurança e medo. Eles percebem que as escolas médicas não os preparam plenamente para os desafios da profissão. A ausência de disciplinas desenvolvedora da capacidade, habilidade e atitude empreendedoras também se mostrou importante na percepção da adversidade, tanto pelos respondentes de todas as fases da trajetória da carreira. As falas dos respondentes expressam bem essa opinião: "tive a oportunidade de continuar no hospital das clínicas que é uma referência na América Latina, mesmo assim, a gente sai se sentindo inseguro (E18)"; "a faculdade não prepara o aluno para o exercício da profíssão na vida real, ela prepara o aluno para ser médico e esquece que hoje a parte financeira é o que dita as regras no exercício da medicina (E24)"; "existe a insegurança de quem sai da faculdade, a faculdade não te forma 100\%"(E19); "a gente sai da faculdade totalmente despreparado para saber o que é abrir uma empresa, dar um plantão como pessoa jurídica, a gente sai bem perdido"(E15); "agora com 10 anos de formado que eu estou começando a ver isso e aprender um pouco mais sobre como funciona todo esse mercado empreendedor"(E23).

Os aspectos socioeconômico e cultural abordaram questões culturais, econômicas e a experiência e vivência sociais. As questões culturais, são caracterizadas pelas especificidades e comportamentos característicos dos profissionais de saúde de uma região ou localidade. A fala do E32 expressa bem essa questão: "a medicina está ligada profundamente à condição sócio cultural e econômica de uma população, você vive isso daí. As respostas dos médicos dependem muito do cenário em que ele está, depende da posição que você ocupa e da localidade".

O mesmo aconteceu com as questões econômicas mencionadas como relevantes pelos médicos pertencentes à fase 2 da carreira. Para eles, os pacientes com baixa renda e educação, demonstram ter mais dificuldade de aderirem ao tratamento. Essa informação é corroborada pelos dizeres do E16: "como eu lidava com uma população de condição financeira bem menor, um pessoal bem mais humilde que não tinha tanto acesso à informação [...] tinha certa ignorância em termos de aderir ao tratamento".

As vivências e experiências dos médicos mostraram-se fundamentais na percepção das adversidades e permitiram identificar a importância do desenvolvimento do aprendizado que normalmente acontece com os erros e acertos na superação das dificuldades. As falas a seguir expressam bem essa questão: "[...] é como lá no começo da residência, eu ficava muito preocupada, chegava em casa, contava para todo mundo que eu havia errado e ficava tentando buscar suporte de alguém para me deixar mais tranquila [...], então, eu acho que a gente vai melhorando essa resiliência, vai aceitando mais, sempre aprendendo com os casos em que a gente errou" (E4); "noto mudanças na minha maneira de agir diante das situações de risco porque aprendo com o que fiz de errado e com o que eu poderia ter feito de diferente para obter um melhor resultado" (E2).

Com relação à tipologia das adversidades, constatou-se três fontes principais geradoras de estresse na profissão médica: dificuldades inerentes à profissão, condições de trabalho e gestão de negócios. As adversidades inerentes à profissão agruparam 8 tipos: judicialização da saúde, relacionamento médico-paciente/família, carreira baseada em evidências científicas, risco físico, risco de adquirir doenças, erro médico, problemas de saúde mental e insatisfação do paciente. Essas adversidades relacionam-se entre si e não são excludentes. No entanto, há uma discrepância na percepção em relação às mesmas. Apenas os riscos da judicialização da saúde e risco físico foram mencionados pelos médicos em todas as fases da trajetória da carreira. A sensação de mal-estar, desesperança, estresse e o desestímulo dos médicos no

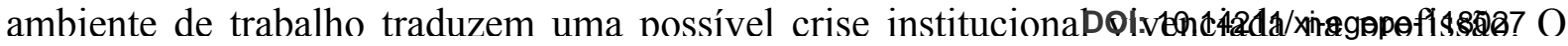


na relação médico-paciente pode ser interpretado como evidências incontestáveis da ruptura entre as partes. A deterioração da relação médico-paciente também explica a busca dos pacientes por informações de saúde na internet. Exercer a profissão médica baseada em evidências científicas torna-se um grande desafio quando os pacientes buscam se autodiagnosticar a partir de informações disponíveis em sites de buscas. O risco físico também foi mencionado pelos médicos como uma das adversidades a serem enfrentadas na profissão.

Uma síntese das dificuldades inerentes à profissão vivenciadas pelos pesquisados, os tipos de dificuldades e a percepção das dificuldades por fase de carreira e exemplos das falas dos pesquisados são identificadas na Figura 1.

\begin{tabular}{|c|c|c|c|c|c|}
\hline \multicolumn{5}{|c|}{ Adversidades } & \multirow[t]{3}{*}{ Quotations } \\
\hline \multirow[t]{2}{*}{ Tipologia } & \multirow[t]{2}{*}{ Propriedades } & \multirow{2}{*}{$\begin{array}{l}\text { Alunos } \\
\text { (Fase 1) }\end{array}$} & \multicolumn{2}{|c|}{ Médicos } & \\
\hline & & & (Fase2) & (Fase 3) & \\
\hline \multirow{7}{*}{ 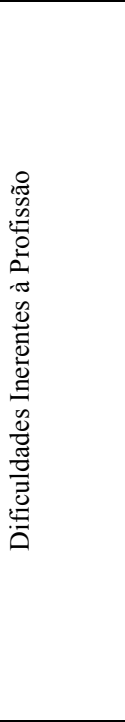 } & Judicialização da Saúde & $\mathrm{X}$ & $\mathrm{X}$ & $\mathrm{X}$ & $\begin{array}{l}\text { "Eu acho que o número de processos tem crescido, não } \\
\text { só por volume, mas porque os pacientes não entendem } \\
\text { que não está tudo ao poder do médico". (E15) }\end{array}$ \\
\hline & $\begin{array}{l}\text { Relacionamento Médico- } \\
\text { Paciente }\end{array}$ & & $\mathrm{X}$ & $\mathrm{X}$ & $\begin{array}{l}\text { "[...] os cuidados com o paciente, os perigos que } \\
\text { envolvem a relação médico-paciente. A gente tem que } \\
\text { ter muito cuidado para não fazer nada errado". (E17) }\end{array}$ \\
\hline & $\begin{array}{l}\text { Carreira baseada em } \\
\text { Evidências Científicas }\end{array}$ & & $\mathrm{X}$ & & $\begin{array}{l}\text { "Acho que a maior dificuldade [...] é conseguir seguir a } \\
\text { sua carreira baseada em evidencias científicas". (E16) }\end{array}$ \\
\hline & Risco Físico & $\mathrm{X}$ & $\mathrm{X}$ & $\mathrm{X}$ & $\begin{array}{l}\text { "Hoje o médico, principalmente quem trabalha com } \\
\text { gente de milicia, ele corre o risco fisico. Muitas vezes ele } \\
\text { se defronta com um pacientelusuário que tem uma } \\
\text { determinada expectativa com o qual ele concorda com } \\
\text { uma conduta técnica, e a gente vê casos de médicos } \\
\text { sendo agredidos fisicamente porque não fizeram aquilo } \\
\text { que o paciente queria que fosse feito - risco fisico". } \\
\text { (E32) }\end{array}$ \\
\hline & $\begin{array}{l}\text { Risco Patológico e } \\
\text { Insatisfação do Paciente }\end{array}$ & $\mathrm{X}$ & & $\mathrm{X}$ & $\begin{array}{l}\text { "Risco de vida, risco de adquirir alguma doença, } \\
\text { periculosidade nos locais de trabalho". (P1a) }\end{array}$ \\
\hline & Erro Médico & $\mathrm{X}$ & & & $\begin{array}{l}\text { "Risco de um erro na profissão porque o erro tem } \\
\text { consequência grave e o risco de insatisfação dos } \\
\text { pacientes de qualquer modo". ( } \mathrm{P} 6 \mathrm{a})\end{array}$ \\
\hline & Problemas de Saúde Mental & $\mathrm{X}$ & & & "Risco de adoecimento da saúde mental”. (P4a) \\
\hline
\end{tabular}

Figura 1 Síntese das Dificuldades Inerentes à Profissão

Fonte: Dados da Pesquisa.

As condições de trabalho contemplam as dificuldades relativas aos recursos tecnológicos, humanos, financeiros, carga horária de trabalho, fluxo de atendimento, risco sistêmico e a pasteurização da saúde. Os dados dessa tipologia não demonstraram unanimidade em nenhum dos itens mencionados pelos respondentes. Os recursos tecnológicos, por exemplo, foram mencionados como adversidade pelos especialistas e pelos profissionais pertencentes à fase 3 da carreira. $\mathrm{O}$ fluxo de atendimento foi mencionado pelos profissionais pertencentes às fases 2 e 3 da carreira. Os recursos financeiros e a carga horária excessiva de trabalho foram mencionados pelos profissionais pertencentes à fase 2 da carreira. $\mathrm{O}$ risco sistêmico e a pasteurização da saúde foram mencionadas pelos especialistas. A dificuldade de lidar com os profissionais de saúde com baixa qualificação foi mencionada pelos médicos pertencentes à fase 3 da carreira. Os alunos do último ano do curso de Medicina, pertencentes à fase 1 da carreira, não indicaram nenhuma das adversidades aglutinadas na dimensão Condições de Trabalho.

Esses achados são consistentes com as fases de carreira a que os médicos pertencem. Os médicos seniores, especialmente aqueles acima de 53 anos de idade e que pertencem à fase 3 da carreira, mencionaram mais dificuldade de acompanhar os avanços tecnológicos da área de saúde, fato esse já mencionado pelos especialistas. Os médicos com até dez anos de carreira parecem ter mais dificuldades de lidar com a carga horária elevada porque gostariam de ter mais tempo para cuidar das suas famílias, filhos pequenos e lazer. A remuneração também tem sido um problema para os jovens médicos. Como os alunos ainda não tiveram

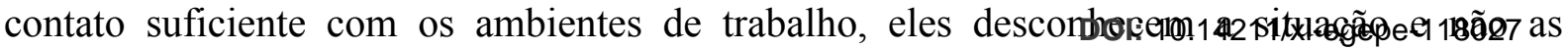



relacionadas às condiçoes de trabalho na percepçăo dos entrevistados.

\begin{tabular}{|c|c|c|c|c|c|}
\hline \multicolumn{5}{|c|}{ Adversidades } & \multirow[t]{3}{*}{ Quotations } \\
\hline \multirow[t]{2}{*}{ Tipologia } & \multirow[t]{2}{*}{ Propriedades } & \multirow{2}{*}{$\begin{array}{l}\text { Alunos } \\
\text { (Fase 1) }\end{array}$} & \multicolumn{2}{|c|}{ Médicos } & \\
\hline & & & (Fase2) & (Fase 3) & \\
\hline \multirow{6}{*}{ 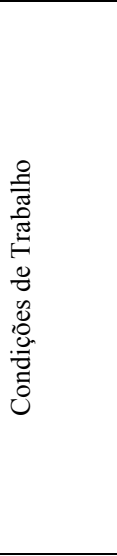 } & Recursos Tecnológicos & & & $\mathrm{X}$ & $\begin{array}{l}\text { "Muitas vezes você está lidando com uma situação adversa } \\
\text { sem recurso. No final das contas, se tudo der errado, o } \\
\text { responsável acaba sendo o profissional". (E24) }\end{array}$ \\
\hline & Recursos Humanos & & & $\mathrm{X}$ & $\begin{array}{l}\text { "O aumento do número de profissionais, muitos não } \\
\text { habilitados". (E14) }\end{array}$ \\
\hline & Recursos Financeiros & & $\mathrm{X}$ & & $\begin{array}{l}\text { "Mas realmente é uma sobrecarga de trabalho, para uma } \\
\text { remuneração não tão justa, na minha opinião". (E15) }\end{array}$ \\
\hline & Carga Horária de Trabalho & & $\mathrm{X}$ & & $\begin{array}{l}\text { "Manejar o paciente, ter um bom resultado cirúrgico, sem } \\
\text { falar na carga horária dos plantões". (E23) }\end{array}$ \\
\hline & Fluxo de Atendimento & & $\mathrm{X}$ & $\mathrm{X}$ & $\begin{array}{l}\text { "Esse fluxo de pacientes é uma preocupação do dia-a-dia, } \\
\text { então a gente se preocupa muito". (E20) }\end{array}$ \\
\hline & $\begin{array}{l}\text { Risco Sistêmico e } \\
\text { Pasteurização da Saúde }\end{array}$ & & & $\mathrm{X}$ & $\begin{array}{l}\text { "O terceiro risco, a gente chama de risco sistêmico [...] e o } \\
\text { risco de pasteurização da assistência. Eu acho que é } \\
\text { importante que você trabalhe com protocolos que sejam } \\
\text { suscetíveis de mensuração de resultado, mas o que a gente } \\
\text { está vendo [...]. O médico acaba tendo que trabalhar muito } \\
\text { de uma maneira não técnica". (P31) }\end{array}$ \\
\hline
\end{tabular}

Figura 2 Síntese das Dificuldades Relacionadas às Condições de Trabalho

Fonte: Dados da Pesquisa.

A gestão de negócios é a preocupação mais recente dentre as adversidades mencionadas pelos médicos. É interpretada como um dos desafios enfrentados por estes profissionais em relação à sua capacidade de empreender e gerir os novos modelos de negócios. As adversidades decorrem dos altos custos de manutenção do negócio, da necessidade de estreitar relacionamentos com as demais partes interessadas, excesso de burocracia, necessidade de ter uma visão estratégica do seu negócio, da importância de estabelecer processos e metas capazes de aumentar a eficiência dos serviços. Todos esses itens foram mencionados como adversidade pelos médicos pertencentes à fase 3 da carreira. Os alunos e os médicos pertencentes à fase 2 da carreira não mencionaram esses itens como adversidades e relevantes.

Esses resultados não surpreendem porque os médicos no início da carreira ainda estão se desenvolvendo, reconhecendo o seu ambiente de trabalho e avaliando as oportunidades disponíveis. Pode-se dizer que muitos ainda não tiveram tempo suficiente para iniciar novos negócios, de criarem suas equipes e formarem as parcerias necessários para empreender nessa área. Ao que tudo indica, o espírito empreendedor começa a ser desenvolvido na fase 3 da carreira médica quando consolidam as suas competências inovadoras, dentre elas 0 questionamento da profissão. É nesta fase que eles estabelecem associações, experimentações, conexões e observam as oportunidades de inovar e firmar novos negócios. A capacidade de lidar com as incertezas, tomar decisões, reconhecer padrões e estabelecer correlações desenvolvidas ao longo da trajetória da carreira médica são fundamentais para o sucesso empreendedor. A Figura 3 traz a síntese das dificuldades relacionadas à Gestão de Negócios.

\begin{tabular}{|c|c|c|c|c|c|}
\hline \multicolumn{5}{|c|}{ Adversidades } & \multirow[t]{3}{*}{ Quotations } \\
\hline \multirow[t]{2}{*}{ Tipologia } & \multirow[t]{2}{*}{ Propriedades } & \multirow{2}{*}{$\begin{array}{c}\text { Alunos } \\
\text { (Fase 1) }\end{array}$} & \multicolumn{2}{|c|}{ Médicos } & \\
\hline & & & (Fase2) & (Fase 3) & \\
\hline \multirow{3}{*}{ 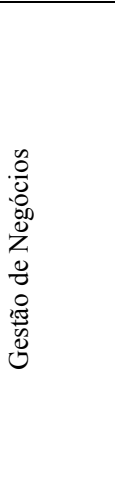 } & Modelos de Negócios & & & $\mathrm{X}$ & $\begin{array}{l}\text { "O médico tem que lidar com a vida, morte e ainda } \\
\text { tem isso ai de empreendedorismo. Hoje em dia, cada } \\
\text { vez mais, o pessoal posta vídeos na internet. A parte } \\
\text { digital da propaganda esbarra até na parte ética do } \\
\text { negócio, o que pode e o que não pode ser feito ou } \\
\text { exposto. Acho que isso é um desafio". (E23) }\end{array}$ \\
\hline & Custos de Manutenção & & & $\mathrm{X}$ & $\begin{array}{l}\text { "Para montar o meu consultório eu tenho que ter um } \\
\text { seguro de todos os aparelhos. Os aparelhos de } \\
\text { oftalmologia são muito caros e todo mundo rouba". } \\
\text { (E3) }\end{array}$ \\
\hline & Gestão & & & $\mathrm{X}$ & 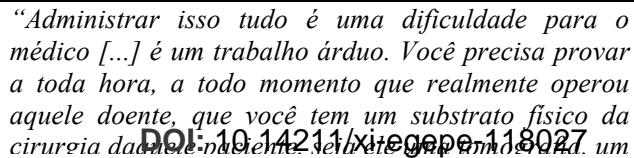 \\
\hline
\end{tabular}




\begin{tabular}{|l|l|l|l|} 
& & & $\begin{array}{l}\text { tempo e trabalno. Parece ser simples, mas nao e . } \\
\text { (E20) }\end{array}$ \\
\hline $\begin{array}{l}\text { Relacionamento com as } \begin{array}{l}\text { Operadoras e Seguradoras de } \\
\text { Saúde }\end{array} \\
\text { "Na verdade, a maior dificuldade hoje é o } \\
\text { gerenciamento dos convênios. Quando você vai } \\
\text { empreender, você depende do mercado de convênios". } \\
\text { (E24) }\end{array}$ \\
\hline
\end{tabular}

Figura 3 Síntese das Dificuldades Relacionadas à Gestão de Negócios Fonte: Dados da Pesquisa.

As consequências das adversidades refletem na afetividade e na vida pessoal dos médicos. São expressas pelos sentimentos de indiferença, frustração, pressão, nervosismo, ansiedade, tensão, vulnerabilidade, chateação, medo, insegurança, tristeza, impotência, mistura de sentimentos, estresse e o cansaço/esgotamento físico e psicológico. A ansiedade, por exemplo, foi mencionada por médicos em todas as fases da carreira, incluindo os alunos pertencentes à fase 1. Esse sentimento considerado desagradável caracteriza a preocupação e inquietação generalizada frente às adversidades e que, por vezes, afetam o bem-estar psicológico do médico. Similares ao sentimento de ansiedade, são os sentimentos de medo mencionado pelos alunos e a pressão citada pelos médicos pertencentes à fase 2 da carreira. Ambos são expressos quando os próprios médicos cobram de si ou é cobrado por terceiros pela entrega de resultados que nem sempre depende exclusivamente do seu papel e do seu conhecimento. A frustração também foi mencionada pelos especialistas e médicos pertencentes à fase 2 e 3 da carreira e caracteriza a impotência frente as adversidades. Geralmente, esse sentimento é expresso quando os médicos criam uma expectativa ou desejo que não é satisfatório no ambiente de trabalho. A impotência frente às dificuldades inerentes à profissão e o contexto foi citada pelos especialistas e médicos pertencentes à fase 2 da carreira. Essa mistura de sentimentos causa nervosismo e tensão. Esses acometimentos geram o cansaço e esgotamento físico e psicológico (fase 2 da carreira). O estresse é a consequência dessa mistura de sentimento, tendo sido mencionado pelos médicos pertencentes à fase $2 \mathrm{da}$ carreira.

Os alunos manifestaram um sentimento de insegurança diante da necessidade de enfrentarem essas adversidades no ambiente de trabalho. A indiferença foi o sentimento mencionado pelos médicos da fase 3 da carreira. Ela caracteriza o indício de uma estratégia emocional de fuga frente às adversidades.

As adversidades também impactam negativamente na vida dos médicos, especialmente os que estão no início da carreira ou com até 10 anos de formado (fase 2). A falta de tempo e a dificuldade de equilibrar a vida pessoal e profissional foram mencionadas por esses profissionais como consequências das adversidades. Figura 4 traz a síntese dos aspectos afetivos, consequentes da Adversidade por Fase de Carreira.

\begin{tabular}{|c|c|c|c|c|c|}
\hline \multicolumn{5}{|c|}{ Consequência das Adversidades } & \multirow[t]{3}{*}{ Quoatations } \\
\hline \multirow[t]{2}{*}{ Tipos } & \multirow[t]{2}{*}{ Propriedades } & \multirow{2}{*}{$\begin{array}{l}\text { Alunos } \\
\text { (Fase 1) }\end{array}$} & \multicolumn{2}{|c|}{ Médicos } & \\
\hline & & & (Fase 2) & (Fase 3) & \\
\hline \multirow{6}{*}{ 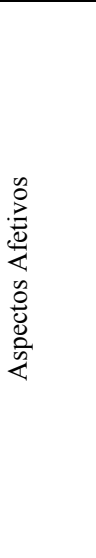 } & Indiferença & & & $\mathrm{X}$ & $\begin{array}{l}\text { "[...] a gente aprende a ser mais indiferente a isso, até } \\
\text { meio frio. [...] um dia você fica mais abatido, abalado, } \\
\text { mas esquece, passa e você aprende a lidar, porque se } \\
\text { não for assim, você acaba se desgastando mentalmente } \\
\text { na profissão". (E13) }\end{array}$ \\
\hline & Frustração & & $\mathrm{X}$ & $\mathrm{X}$ & $\begin{array}{l}\text { "É a frustração. Frustração total, principalmente na } \\
\text { rede pública. Revolta. Acho que essa é a palavra: } \\
\text { revolta". (E24) }\end{array}$ \\
\hline & Pressão & & $\mathrm{X}$ & & $\begin{array}{l}\text { "Pressão, eu acho que a pressão é muito grande em } \\
\text { erros médicos e coisas assim". (E15) }\end{array}$ \\
\hline & Nervosismo & & $\mathrm{X}$ & & $\begin{array}{l}\text { "Reajo com nervosismo e ansiedade ao enfrentar essas } \\
\text { situações de risco". (E2) }\end{array}$ \\
\hline & Ansiedade & $\mathrm{X}$ & $\mathrm{X}$ & $\mathrm{X}$ & $\begin{array}{l}\text { "Ansiedade, o principal é a ansiedade. É só saber lidar } \\
\text { com a ansiedade, tentar administrar com calma". (E23) }\end{array}$ \\
\hline & Vulnerabilidade & $\mathrm{X}$ & & & $\begin{array}{l}\text { "Acho que a gente fica vulnerável diante de toda a } \\
\text { situação e a gente não tem o que fazer e acaba } \\
\text { aceitando". (DOD): 10.14211/xi-egepe-118027 }\end{array}$ \\
\hline
\end{tabular}




\begin{tabular}{|c|c|c|c|c|c|}
\hline & Chateaçao & & & $X$ & $\begin{array}{l}\text { Voce flca chateado porque quando voce faz medicına } \\
\text { você quer cuidar da pessoa". (E3) }\end{array}$ \\
\hline & Mistura de Sentimentos & & $\mathrm{X}$ & $\mathrm{X}$ & $\begin{array}{l}\text { "A Medicina não é o que parece na TV, que é só } \\
\text { felicidade, paciente te agradecendo o dia inteiro, te } \\
\text { dando presentes e você salvando vida o dia inteiro. É } \\
\text { uma mistura de sentimentos". (E15) }\end{array}$ \\
\hline & $\begin{array}{l}\text { Cansaço/esgotamento físico e } \\
\text { psicológico }\end{array}$ & & $\mathrm{X}$ & & $\begin{array}{l}\text { "Quando não estou de plantão, só penso em dormir e } \\
\text { tentar me recuperar fisicamente e psicologicamente". } \\
\text { (E2) }\end{array}$ \\
\hline & Medo & $\mathrm{X}$ & & & $\begin{array}{l}\text { "Acho que eles têm bastante medo de dar errado. Têm } \\
\text { medo de náo conseguir fazer o que tem que ser feito na } \\
\text { hora, medo de perder o paciente. O sentimento maior } \\
\text { que emerge é o medo". (P1a) }\end{array}$ \\
\hline & Insegurança & $\mathrm{X}$ & & & $\begin{array}{l}\text { "Acho que podemos definir esse sentimento como uma } \\
\text { insegurança constante. Isso vai desgastar muito o } \\
\text { médico, fisica e psicologicamente". (P8a) }\end{array}$ \\
\hline & Tristeza & & $\mathrm{X}$ & $\mathrm{X}$ & $\begin{array}{l}\text { "[...] nos momentos ruins, eu me sentia triste e essa } \\
\text { sensação de impotência perdurou por meses". (E2) }\end{array}$ \\
\hline & Impotência & & $\mathrm{X}$ & $\mathrm{X}$ & $\begin{array}{l}\text { "Quando você não consegue resolver a situação, pode } \\
\text { ser um sentimento de impotência diante de um problema } \\
\text { que se apresenta". ( } \mathrm{P} 2 \mathrm{e})\end{array}$ \\
\hline & Estresse & & $\mathrm{X}$ & & $\begin{array}{l}\text { Na verdade, é que eu não ando tendo muito tempo para } \\
\text { estudar como eu estudava antes. Então, isso me inquieta, } \\
\text { me deixa muito estressada". (E1) }\end{array}$ \\
\hline 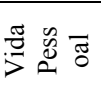 & $\begin{array}{l}\text { Dificuldades de Equilibrar a } \\
\text { Vida Pessoal e Profissional }\end{array}$ & & $\mathrm{X}$ & & $\begin{array}{l}\text { "Isso impacta na minha vida pessoal. Para estudar, eu } \\
\text { tenho que abrir mão de alguma coisa". (E1) }\end{array}$ \\
\hline
\end{tabular}

Figura 4 Síntese dos Consequentes da Adversidade por Fase de Carreira

Fonte: Dados da Pesquisa

As EE relacionam-se às respostas dos médicos frente à situação estressante. Elas refletem a forma com que estes profissionais lidam com os agentes geradores de estresse no ambiente de trabalho. Nessa pesquisa, os médicos demonstraram EE diferenciadas. As estratégias focadas na capacidade afetiva são compreendidas pela espiritualidade, empatia, a calma e serenidade (fase 2 da carreira). A empatia é comum entre os médicos pertencentes à fase 3. As falas exemplificam as estratégias com foco na afetividade: "essa espiritualidade, ela veio desde sempre, Deus foi sempre muito importante na minha vida e isso é o que mais contribui para o enfrentamento das dificuldades" (E1); "[..], eu me coloco mais no lugar do paciente $[\ldots]$ assim você consegue aconselhar melhor"(E16).

As estratégias focadas nas capacidades cognitivas são representadas pela aproximação dos pacientes/familiares, registro nos prontuários, orientação e conversa aos pacientes, uso de protocolos, uso da razão; raciocínio, busca pelo conhecimento, valer-se da assertividade, prontidão, atitude, memória e as capacidades de pensar, estudar, trabalhar, observar, realizar, inovar, transformar, decidir, criar ouvir e agir. A vivência, por exemplo, explica a memória diante das situações experienciadas e as estratégias usadas nas diversas fases da carreira. A estratégia de aproximação do paciente e familiares tem sido usadas em todas as fases da carreira. $\mathrm{O}$ conhecimento técnico adquirido na faculdade foi mencionado com estratégia pelos dois grupos focais - especialistas e alunos. Os médicos pertencentes à fase 2 da carreira mencionaram aproximação dos pacientes/familiares, estudo e o trabalho como estratégias para enfrentar as adversidades. Os exemplos ilustram essas experiências: "eu sempre tento ter uma boa relação médico e paciente, o máximo de atenção possível, nunca sou negligente [...]" (E17); "a gente reage trabalhando" (E15); "para enfrentar essas dificuldades ou acontecimentos, estudar sempre" (E2).

Os médicos pertencentes à fase 3 da carreira mencionaram a aproximação dos pacientes/familiares, os cuidados com os registros nos prontuários médicos, habilidades de assertividade e prontidão, a atitude e a memória, uso dos protocolos, orientação dada aos pacientes, priorização da razão e as capacidades de inovar, realizar, transformar, decidir e de criar como EE frente as adversidades. As falas dos respondentes expressam o uso estratégias

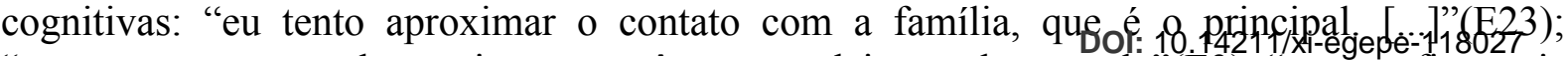


precavido, então, em relação à segurança, a gente tende a usar ma1s protocolos"(E25); "eu acho que a gente tem que raciocinar sobre o que a gente está fazendo. Não pode deixar a emoção tomar conta e você largar tudo, abandonar no meio do processo" (E4); "eu observo, ouço as pessoas e penso" (E18).

Os alunos informaram valer-se da orientação como EE. A fala do P3a corrobora com essa identificação: "a gente procura orientação de outro colega que já passou por isso que tenha alguma informação". Foi evidenciado que os médicos pertencentes à fase 2 da carreira também se apoiam concomitante nos aspectos afetivo e cognitivo. Diante de um enfrentamento, esses profissionais param, analisam a situação com calma e mantêm um pensamento positivo. Esse rápido afastamento contribui para que a situação adversa seja repensada e analisada para que, na sequência, novas atitudes sejam tomadas. Essa relação também pode ser identificada pela sua implicação na autoeficácia e na intenção na autorregulação cognitiva e afetiva nos comportamentos de enfrentamento do indivíduo. Essa evidência é um importante achado da presente pesquisa. A fala do E2 representa a indissociabilidade das capacidades afetivas e cognitivas como EE: "eu mantenho a calma, tenho um pensamento bem objetivo, como se não fosse eu que tivesse ali, eu saio e observo aquela situação por fora e analiso taticamente para ver como eu consigo sair dali da maneira mais prática".

Verificou-se uma possível tendência à reavaliação positiva de alguns profissionais frente às adversidades. Ela é percebida pelo sentimento otimista e pela paixão à profissão que os auxilia no enfrentamento das adversidades. Esse comportamento é expresso pelos E1, E24: "acho que tudo de ruim é uma fase e vai passar e isso não faz parte do meu dia. Eu sou muito positiva"; "eu acho que eu continuo sendo um eterno sonhador de achar que a gente vai conseguir exercer a profissão como deve ser exercida".

Em muitos casos, os médicos pertencentes à fase 2 da carreira contam com o apoio do chefe do serviço na residência médica, dos familiares, da espiritualidade e das redes de relacionamento. Os médicos pertencentes à fase 3 da carreira contam com o apoio dos familiares. As falas reforçam esses achados: "eu acho que imprescindíveis são um apoio familiar e Deus" (E1); "minha esposa é administradora, especializada em finanças e me ajudou ao longo dos anos" (E22); "dificuldades clínicas, em termos de estudo, sempre a pessoas da minha especialidade, a gente tem um grupo no WhatsApp e consegue discutir sempre os problemas clínicos mais raros" (E16).

$\mathrm{O}$ bem-estar decorrente do enfrentamento também pode ser percebido nas falas dos respondentes. Os médicos parecem ter clareza das mudanças que os enfrentamentos promovem em suas vidas. Essas mudanças contribuem para o aprendizado, adaptação, superação e evolução destes profissionais.

O desenvolvimento da capacidade de resiliência empreendedora dos médicos, a depender da fase da carreira em que se encontram, pode ser compreendido pelas capacidades comportamentais e individuais. As capacidades comportamentais são entendidas pelos comportamentos de acomodação/adaptação/aceitação, aprendizado, superação, evolução e defesa. Elas não são excludentes entre si. Os alunos demonstraram comportamentos de aceitação e defesa frente às adversidades. Os médicos pertencentes à fase 2 demonstraram aprender com desafios, superar as adversidades e evoluir. $\mathrm{O}$ mesmo acontece com os médicos pertencentes à fase 3 da carreira, sendo acrescido a sua capacidade de aceitação e acomodação diante das adversidades e de busca por novos projetos empreendedores. Alguns fragmentos para ilustrar: "noto mudanças na minha maneira de agir diante das situações de risco, porque aprendo com o que fiz de errado e no que eu poderia ter feito de diferente para um resultado final melhor" (E2); "acho que com o tempo a gente vai amadurecendo, vai ficando um pouco mais calmo, tranquilo, sossegado" (E27). As capacidades individuais que caracterizam o

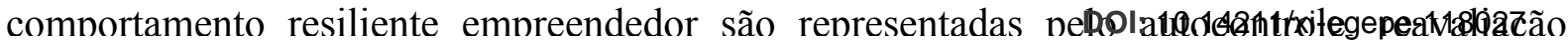


năo são excludentes entre s1. Por exemplo, um indivíduo com autocontrole emocional também pode ser apaixonado pela sua profissão. Ele pode ser precavido ao mesmo tempo em que reavalia as situações adversas positivamente, tendo a convicção de que a situação que se apresenta vai passar. Os alunos mostraram-se precavidos diante das adversidades; os médicos pertencentes à fase 2 da carreira são otimistas e buscam reavaliar positivamente as situações adversas; os médicos pertencentes à fase 3 demonstraram ter autocontrole emocional e cognitivo diante das adversidades. Também são precavidos e apaixonados pelo que fazem.

Esses resultados permitiram a construção das seguintes proposições:

Proposição 1 Os antecedentes da adversidade influenciam o contexto da saúde nas dimensões ambientais, educacionais, socioeconômico e cultural. Eles são percebidos de maneira diferente pelos médicos nas diversas fases da carreira.

Proposição 2 As adversidades percebidas pelos médicos envolvem as condições de trabalho, as dificuldades inerentes à profissão e a gestão de negócios. Para superá-las, os médicos precisam desenvolver habilidades tecnológicas, qualificar pessoas, rever carga horária de trabalho e fazer a gestão administrativa, de mercado e de risco.

Proposição 3 As consequências das adversidades são explicadas pelos aspectos afetivos e pelo impacto na vida pessoal e profissional dos médicos. Os aspectos afetivos influenciam os aspectos cognitivos e vice-versa.

Proposição 4 As dimensões afetivas, cognitivas e de apoio, inerentes à profissão dos médicos, são responsáveis por impactar as EE das adversidades. Essas envolvem aspectos situacionais, relacionais, emocionais e as vivências dos médicos no plano pessoal e profissional.

Proposição 5 As dimensões afetivas, cognitivas, afetivo-cognitivas, e de apoio e espiritualidade podem contribuir para explicar o comportamento resiliente do médico, ao considerar a cultura, o ambiente, os valores pessoais e a educação oferecida aos profissionais.

Proposição 6 A formação, as experiências, as vivências, e os relacionamentos estabelecidos no exercício da profissão médica, são responsáveis pelo desenvolvimento ou não da capacidade resiliente. Este comportamento contempla as competências e os atributos individuais, cujas influências advêm de estruturas ambientais, psíquicas e de valores pessoais.

Proposição 7 Os médicos assumem o papel de empreendedor na fase 3 da trajetória de carreira. Ao assumir esse papel, são vivenciam as dificuldades relacionadas ao modelo do negócio, custo de manutenção, relacionamento com os parceiros e gestão eficiente dos recursos.

Esses achados permitiram a construção de um modelo teórico e empírico sobre o desenvolvimento da capacidade de resiliência empreendedora, que está circunstanciado na Figura 5.

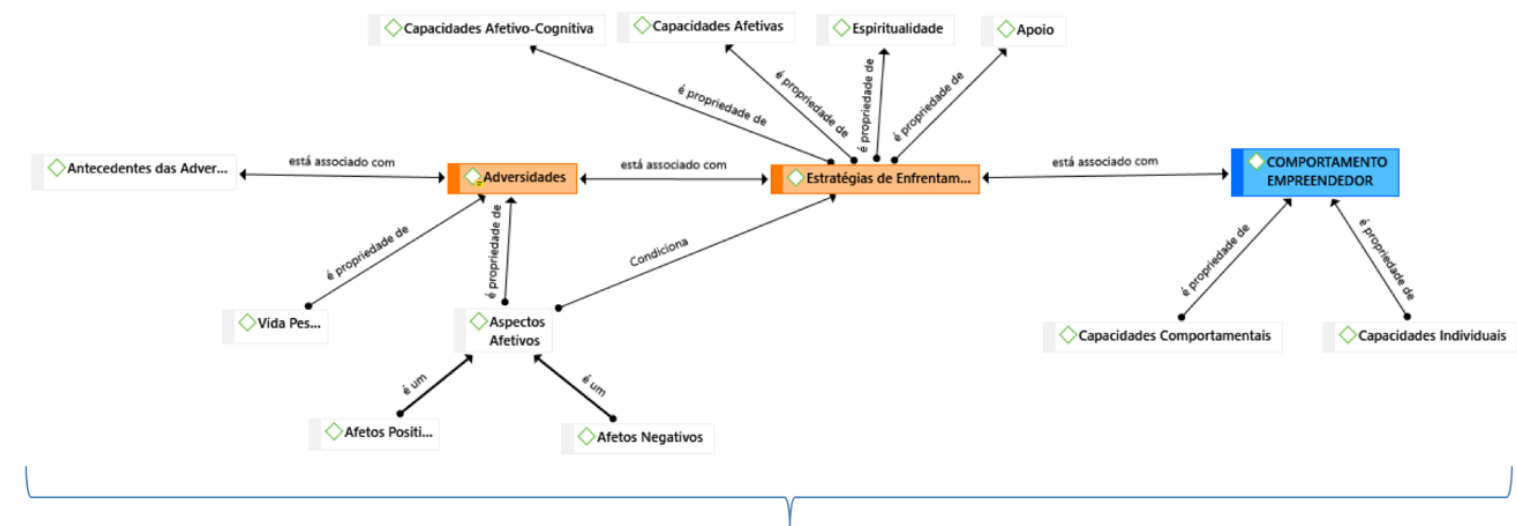

Processo de Desenvolvimento da Capacidade de Resiliência

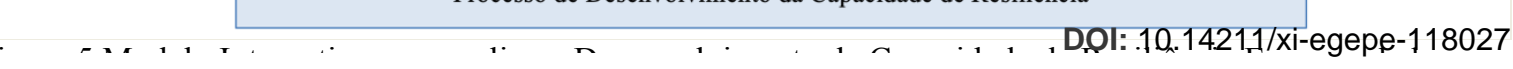




\section{Discussão}

As evidências empíricas descritas na seção anterior sugerem que o desenvolvimento da capacidade de resiliência empreendedora dos médicos pesquisados acontece na sua trajetória de carreira e está vinculado à percepção das adversidades e das estratégias de enfrentamento. As questões de contexto cultural, socioeconômico e institucional interferem no juízo de valores dos médicos pesquisados. Argumenta-se que três categorias explicam a percepção das adversidades enfrentadas no contexto da profissão médica e que emergem nesse estudo: as dificuldades inerentes à profissão, condição de trabalho e gestão de negócios.

Certamente, conhecer as condições geradoras de estresse que influenciam no desenvolvimento das atividades do médico e compreender como elas agem nas diferentes fases da trajetória da carreira deste profissional, constitui uma forma de contribuição para a literatura sobre o desenvolvimento da capacidade de resiliência empreendedora desses profissionais.

Em linha com Duchek (2018), o desenvolvimento da capacidade de resiliência empreendedora está relacionado às forças individuais dos médicos de suportarem as condições geradoras de estresse e às estratégias por eles adotadas para lidar com a pressão. $\mathrm{O}$ presente estudo também encontra similaridade com o proposto por Lee \& Wang (2017), mais especificamente no sentido de buscar compreender a dinamicidade do desenvolvimento da capacidade de resiliência a partir da percepção dos atores, sobre os tipos de adversidades por eles enfrentadas e o impacto destas na escolha das EE, na superação e sobrevivência no mercado.

Portanto, essa pesquisa contribui com a expansão da base teórica na medida em que explica o desenvolvimento da capacidade de resiliência empreendedora em um contexto específico (ambiente da saúde), cujo ator principal (médico) apresenta um perfil peculiar caracterizado pela pluralidade profissional (cuidados com a saúde e bem-estar do paciente e empreendedor). Esse estudo também contribui para explicar em qual fase começa a ser desenvolvimento a resiliência empreendedora dos médicos e como ele se comporta diante das adversidades ao empreendedor.

As capacidades afetivas e cognitivas também contribuíram para melhor explicar as EE das adversidades em cinco dimensões: (1) as estratégias que focam, primordialmente, as capacidades afetivas; (2) as estratégias que focam, primordialmente, as capacidades cognitivas; (3) as estratégias que focam, concomitantemente, as capacidades afetivas e cognitivas, (4) o apoio social e a (5) espiritualidade.

Argumenta-se, ainda, que as EE não são excludentes entre si e que a dinamicidade percebida nas adversidades, capacidades individuais e na singularidade do contexto estudado, facilita as recorrências e as concomitâncias das estratégias nas várias fases da trajetória da carreira do médico. Essas evidências encontram similaridade com os estudos de Folkmam e Lazarus, (1980), Carver et al. (1989) e Uy, Foo e Song (2013), sobre as EE focadas nas emoções dos indivíduos que se distanciam temporariamente da situação geradora do estresse e sobre as EE focadas no problema e/ou na orientação da tarefa mencionada por Folkmam \& Lazarus (1980). Porém, traz como achado relevante, a indissociabilidade das capacidades afetivas e cognitivas enquanto influenciadoras das EE. Esse achado preenche o gap identificado por Nassif (2014) que sugere a indissociabilidade das capacidades cognitivas e afetivas nos estudos sobre o comportamento empreendedor. Também atende aos chamados de Delgado García, Quevedo Puente e Blanco Mazagatos (2015) que sugeriram que estudos no campo do empreendedorismo que integram a afetividade e cognição, possuem uma evolução recente na literatura, havendo uma preocupação com a sua consolidação teórica.

Verificou-se ainda que os médicos, ao assumirem o papel de empreendedores, percebem a gestão de negócios como uma das dificuldades mais significativas no desempenho

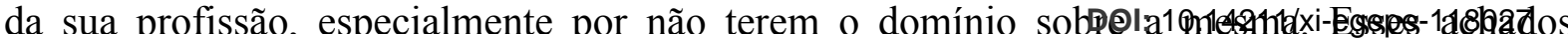


empreendedora do médico (Crick \& Crick, 2016) e aumento da capacidade de sobrevivência do seu empreendimento. Eles são corroborados por Menéndez Blanco, José-Luis MontesBotella (2017) que sugerem que a capacidade de resiliência contribui teoricamente com o avanço das pesquisas no campo do empreendedorismo à medida que trazem elementos importantes para o aumento da capacidade de sobrevivência do médico quando ele assume o papel de empreendedor no mercado.

Por fim, os resultados desse estudo sugerem que a resiliência é explicada por duas categorias: (1) capacidades comportamentais e as (2) capacidades individuais que sinalizam a existência de diferenças sutis nas três fases da trajetória da carreira.

\begin{tabular}{|c|c|}
\hline $\begin{array}{l}\text { Capacidades } \\
\text { comportamentais }\end{array}$ & $\begin{array}{l}\text { As capacidades comportamentais decorrem das inconsistências no ambiente no qual os médicos estão inseridos. Esse } \\
\text { contexto exige dos médicos a necessidade e a capacidade premente de adaptação o que se sobrepõe à lógica das ações } \\
\text { profissionais. Por esse ângulo, as capacidades comportamentais apresentam uma estreita relação com o conhecimento, } \\
\text { habilidades e atitudes profissionais (Trapet, 2000). Argumenta-se, nesse estudo, a existência de cinco capacidades } \\
\text { comportamentais que explicam o comportamento dos médicos frente às adversidades: (1) } \\
\text { acomodação/adaptação/aceitação; (2) aprendizado; (3) superação; (4) evolução e (5) defesa. Essas propriedades } \\
\text { mostraram-se dinâmicas nas diversas fases da carreira. Quando expostos a situações de riscos, decorrentes das } \\
\text { condições de trabalho, usam destas capacidades para esquivar-se de situações futuros. }\end{array}$ \\
\hline $\begin{array}{l}\text { Capacidades } \\
\text { individuais: }\end{array}$ & $\begin{array}{l}\text { Caracterizam as particularidades e características próprias dos médicos pesquisados. Ao que tudo indica, elas são } \\
\text { exclusivas e contribuem para explicar as capacidades comportamentais dos médicos frente às adversidades. Sete } \\
\text { atributos/capacidades foram identificados nas falas dos médicos: (1) autocontrole emocional e cognitivo, (2) } \\
\text { reavaliação positiva; (3) precaução, (4) honestidade, (5) paixão, (6) otimismo e a (7) autoeficácia. Esses } \\
\text { atributos/capacidades não são excludentes entre si. Eles também podem apresentar o efeito de inibição de uma } \\
\text { condição geradora de estresse. }\end{array}$ \\
\hline
\end{tabular}

Figura 6 Características Comportamento do Médico

Fonte: Elaborada pela autora

Ainda conforme percebido na pesquisa empírica, as EE dos médicos mudam de acordo com as fases de carreira e as experiências adquiridas no ambiente de trabalho. Elas são impactadas pelo ambiente que esses médicos se encontram inseridos e pelas capacidades individuais e comportamentais. Esses achados são corroborados pelos dizeres de Antoniazzi, Dell'aglio e Bandeira (1998) ao sugerirem que as modificações nas condições de vida através das experiências, contribuem para as mudanças no comportamento e para a escolha das EE. A despeito disso, essas mudanças parecem preservar a vida e a saúde mental e física dos médicos. Esses achados também encontram similaridade com os dizeres de Straub (2005) que sugere que a dinamicidade dos estímulos estressores modifica as respostas e a interação do indivíduo com o seu ambiente.

Com relação às capacidades individuais identificadas, é possível inferir que todas contribuem positivamente na superação dos contratempos inerentes às condições de trabalho, à profissão e à gestão de negócios. Quando combinadas, podem levar ao alcance de metas, ao esforço no sentido de superação e, principalmente, à satisfação no ambiente de trabalho (Przepiorka, 2016). A autoeficácia mencionada nos estudos de Sutcliffe e Vogus (2003) sinalizam como benéfica para o aumento do desempenho individual e organizacional.

\section{Conclusão}

Esse estudo é explicado por meio de um modelo integrativo dos constructos afetivs, cognitivos, adversidades e estratégia de enfrentamento de um grupo de profissionais médicos em diferentes fases da carreira profissional. Analisa-los a partir das experiências e das adversidades vivenciadas durante a trajetória de carreira culminou no avanço teórico do campo de empreendedorismo, propiciando assim, a compreensão do desenvolvimento da capacidade de resiliência empreendedora que explica o comportamento do médico, demonstrando a originalidade desse estudo.

Não obstante as capacidades cognitivas e afetivas fazerem parte da agenda de pesquisa de alguns autores no campo do empreendedorismo, este estudo traz evidencias empíricas da indissociabilidade destes constructos. Além disso, ele responde aos ensejos pontuados na literatura que sinalizam a necessidade da realização de pesquisas em contextos específicos, aqui desenvolvida junto a um grupo de médicos e estudantes o 
áreas de atuação. Por sua vez, o comportamento empreendedor, que a1nda se encontra alicerçado em uma frágil base teórica, aqui encontra contribuições que avançam o entendimento quando estudado em contextos caracterizados por sua pluralidade e especificidade. Este estudo propõe como agenda de futuras pesquisas a busca de resultados por meio das seis proposições mencionadas, cujo intuito é o de avançar o campo de estudo e propiciar a multidisciplinariedade com a área de empreendedorismo.

\section{Referências}

Andrews, N. (2017). Psychosocial factors influencing the experience of sustainability professionals. Sustainability Accounting, Management and Policy Journal, 8(4), 445-469.

Bardin, L. (2011). Análise de conteúdo. Edições 70. Lisboa. Portugal.

Barrett, L. F. (2006). Solving the emotion paradox: Categorization and the experience of emotion. Personality and Social Psychology Review, 10(1), 20-46

Cano, D. S. (2008). O profissional que está no fio-entre a vida e a morte: Vivências, Concepções e Estratégias de Enfrentamento Psicológico de médicos oncologistas.

Cardon, M. S., Wincent, J., Singh, J., \& Drnovsek, M. (2005, August). Entrepreneurial passion: the nature of emotions in entrepreneurship. In Academy of Management Proceedings (Vol. 2005, No. 1, pp. G1-G6).

Carvalho, Marcus (2017). A realidade do empreendedorismo médico no Brasil. In Admintradores.com. Acesso em 13 junho 2019.

Carver, C. S., Scheier, M. F., \& Weintraub, J. K. (1989). Assessing coping strategies: a theoretically based approach. Journal of Personality and Social Psychology, 56(2), 267.

Clark, S. M. et al. Transitional Identity as a Facilitator of Organizational Identity Change during a Merger. Administrative Science Quarterly, v. 55, n. 3, p. 397-438, 2010.

Creswell, J. W. (2014). A concise introduction to mixed methods research. Sage Publications.

Crick, J. M., \& Crick, D. (2016). Developing entrepreneurial resilience in the UK tourism sector. Strategic Change, 25(3), 315-325.

da Silva, A. B., Godoi, C. K., \& Bandeira-de-Mello, R. (2010). Pesquisa Qualitativa Em Estudos

Organizacionais: Paradigmas, Estratégias E Métodos. Editora Saraiva.

de Azevedo Guido, L., Umann, J., Stekel, L. M. C., da Costa Linch, G. F., da Silva, R. M., \& Lopes, L. F. D.

(2009). Estresse, coping e estado de saúde de enfermeiros de clínica médica em um hospital universitário.

Ciência, Cuidado e Saúde, 8(4), 615-621.

Delgado García, J. B., De Quevedo Puente, E., \& Blanco Mazagatos, V. (2015). How affect relates to entrepreneurship. International Journal of Management Reviews, 17(2), 191-211

Deliens, T., Deforche, B., De Bourdeaudhuij, I., \& Clarys, P. (2015). Determinants of physical activity and sedentary behaviour in university students. BMC public health, 15(1), 201.

Duchek, S. (2018). Entrepreneurial resilience: a biographical analysis of successful entrepreneurs. International Entrepreneurship and Management Journal, 14(2), 429-455.

Ekman P. An argument for basic emotions. Cognition and Emotion. 1992; 6:169-200.

Elliott, D., \& Macpherson, A. (2010). Policy and practice: Recursive learning from crisis. Group \& Organization Management, 35(5), 572-605.

Ellsworth, P. C., \& Scherer, K. R. (2003). Appraisal processes in emotion. Handbook of affective sciences, 572.

Folkman, S., \& Lazarus, R. S. (1980). An analysis of coping in a middle-aged community sample. Journal of Health and Social Behavior, 219-239.

Fontana, A., \& Frey, J. H. (2000). The interview: From structured questions to negotiated text. Handbook of qualitative research, 2(6), 645-672.

Frijda, N. H. (1986). The emotions. Cambridge University Press.

Garbuio, M., \& Wilden, R. (2018). Entrepreneurship in Healthcare. In Entrepreneurship in Healthcare (pp. 1942). Routledge.

Gioia, D. A., Corley, K. G., \& Hamilton, A. L. (2013). Seeking qualitative rigor in inductive research: Notes on the Gioia methodology. Organizational research methods, 16(1), 15-31.

Gross, J. J., \& John, O. P. (2003). Individual differences in two emotion regulation processes: implications for affect, relationships, and well-being. Journal of Personality and Social Psychology, 85(2), 348.

Halkos, G., Skouloudis, A., Malesios, C., \& Evangelinos, K. (2018). Bouncing Back from Extreme Weather Events. Business Strategy and the Environment, 27(4), 547-559.

Herbane, B. (2015). Threat orientation in small and medium-sized enterprises: Understanding differences toward acute interruptions. Disaster Prevention and Management, 24(5), 583-595.

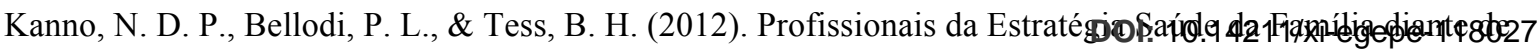


Kaplan, S., LaPort, K., \& Waller, M. J. (2013). The role of positive aftectivity in team effectiveness during crises. Journal of Organizational Behavior, 34(4), 473-491.

Lazarus, R. S. (1991). Progress on a cognitive-motivational-relational theory of emotion. American psychologist, 46(8), 819.

Lerner, J. S., \& Keltner, D. (2000). Beyond valence: Toward a model of emotion-specific influences on judgement and choice. Cognition \& Emotion, 14(4), 473-493.

Lerner, J. S., \& Keltner, D. (2001). Fear, anger, and risk. Journal of personality and social psychology, 81(1). Lerner, J. S., \& Tiedens, L. Z. (2006). Portrait of the angry decision maker: How appraisal tendencies shape anger's influence on cognition. Journal of behavioral decision making, 19(2), 115-137.

Linnenluecke, M. K., \& Griffiths, A. (2015). The climate resilient organization: Adaptation and resilience to climate change and weather extremes. Edward Elgar Publishing.

Lottridge, D., Chignell, M., \& Jovicic, A. (2011). Affective interaction: Understanding, evaluating, and designing for human emotion. Reviews of Human Factors and Ergonomics, 7(1), 197-217.

Luthans, F., Avolio, B. J., Avey, J. B., \& Norman, S. M. (2007). Positive psychological capital: Measurement and relationship with performance and satisfaction. Personnel psychology, 60(3), 541-572.

Magnago, C., \& Pierantoni, C. R. (2015). Dificuldades e estratégias de enfrentamento referentes à gestão do trabalho na Estratégia Saúde da Família, na perspectiva dos gestores locais. Saúde em Debate, 39, 9-17.

Masten, A. S. (2001). Ordinary magic: Resilience processes in development. American Psychologist, 56(3) Mayordomo, T., Viguer, P., Sales, A., Satorres, E., \& Meléndez, J. C. (2016). Resilience and coping as predictors of well-being in adults. The Journal of Psychology, 150(7), 809-821.

McNaughton, R. B., \& Gray, B. (2017). Entrepreneurship and resilient communities-introduction to the special issue. Journal of Enterprising Communities: People and Places in the Global Economy, 11(1), 2-19.

Merriam, S. B. (2009). Qualitative research: A guide to design and implementation. SF, CA: Jossey-Bass.

Mitchelmore, S., \& Rowley, J. (2010). Entrepreneurial competencies: a literature review and development agenda. International journal of entrepreneurial Behavior \& Research, 16(2), 92-111.

Morero, J. A. P., Bragagnollo, G. R., \& Santos, M. T. S. (2018). Estratégias de enfrentamento: uma revisão sistemática sobre instrumentos de avaliação no contexto brasileiro. Revista Cuidarte, 9(2), 2257-2268.

Ngah, R., \& Salleh, Z. (2015). Emotional intelligence and entrepreneurs' innovativeness towards entrepreneurial success: A preliminary study. American Journal of Economics, 5(2), 285-290.

Osiyevskyy, O., \& Dewald, J. (2015). Inducements, impediments, and immediacy: exploring the cognitive drivers of small business managers' intentions to adopt business model change. Journal of Small Business Management, 53(4), 1011-1032.

Patzelt, H., \& Shepherd, D. A. (2011). Negative emotions of an entrepreneurial career: Self-employment and regulatory coping behaviors. Journal of Business venturing, 26(2), 226-238.

Reisenzein, R. (2001). Appraisal processes conceptualized from a schema-theoretic perspective: Contributions to a process analysis of emotions.

Ruskin, J., Seymour, R. G., \& Webster, C. M. (2016). Why create value for others? An exploration of social entrepreneurial motives. Journal of Small Business Management, 54(4), 1015-1037.

Seo, M. G., Barrett, L. F., \& Bartunek, J. M. (2004). The role of affective experience in work motivation. Academy of Management Review, 29(3), 423-439.

Shepherd, D. A., Saade, F. P., \& Wincent, J. (2019). How to circumvent adversity? Refugee-entrepreneurs' resilience in the face of substantial and persistent adversity. Journal of Business Venturing.

Smedley, J. (2018). Enhancing information impact: how do we make the most of our information senses? Information and Learning Science, 119(3/4), 142-144.

Smith, J. L., \& Hollinger-Smith, L. (2015). Savoring, resilience, and psychological well-being in older adults. Aging \& Mental Health, 19(3), 192-200.

Sommer, S. A., Howell, J. M., \& Hadley, C. N. (2016). Keeping positive and building strength. Group \& Organization Management, 41(2), 172-202.

Uy, M. A., Foo, M. D., \& Song, Z. (2013). Joint effects of prior start-up experience and coping strategies on entrepreneurs' psychological well-being. Journal of Business Venturing, 28(5), 583-597.

Van Der Vegt, G. S., Essens, P., Wahlström, M., \& George, G. (2015). Managing Risk and Resilience: From the Editors. (2015). Academy of Management Journal. 58, (4), 971-980.

Wagstaff, C. R., Gilmore, S., \& Thelwell, R. C. (2016). When the show must go on: Investigating repeated organizational change in elite sport. Journal of Change Management, 16(1), 38-54.

Williams, N., Vorley, T., \& Ketikidis, P. H. (2013). Economic resilience and entrepreneurship: A case study of the Thessaloniki City Region. Local Economy, 28(4), 399-415.

Zonta, R., Robles, A. C. C., \& Grosseman, S. (2006). Estratégias de enfrentamento do estresse desenvolvidas por

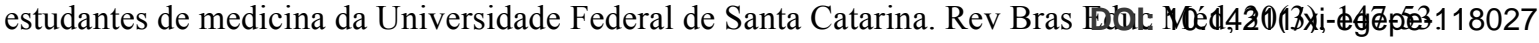

